\title{
Effect of extraction solvents on phenolic contents and antioxidant capacities of Artocarpus chaplasha and Carissa carandas fruits from Bangladesh
}

\author{
Gouri Dhar, Sonam Akther, Afrin Sultana, Uchen May, Mohammed Moinul Islam, Mowri Dhali, Dwaipayan Sikdar ${ }^{*}$ \\ Department of Biochemistry and Molecular Biology, University of Chittagong, Chittagong-4331, Bangladesh.
}

\section{ARTICLE INFO}

Article history:

Received on: 13/01/2017

Accepted on: 23/03/2017

Available online: 19/06/2017

Key words:

Phenolic contents, Flavonoids, Antioxidant activity, Solvent effect, Fruits.

\begin{abstract}
Increased intake of fruits, due to their high antioxidant capacity, is known to reduce the risk of many diseases. The high antioxidant capacity of fruits is attributed by the presence of phenolics. The aim of the present study was to evaluate how solvents affect the extraction of phenolic and flavonoid substances and the antioxidant activity of fruit extracts of $A$. chaplasha and $C$. carandas. The fruits were extracted using water and various concentrations (50\%, 70\% and pure) of methanol, ethanol and acetone in water as solvent. Phenolic and flavonoid contents were measured by Folin-Ciocalteu method and aluminum trichloride method respectively. Antioxidant activity was measured by DPPH free radical scavenging assay. The efficiency of solvents in extracting phenols varied considerably for both fruits. Phenolic content and antioxidant activity was highest in $70 \%$ acetone extract and lowest in $100 \%$ acetone extract whilst flavonoid content was highest in pure ethanol extracts of both fruit. Strong correlation was found between the phenolic contents and antioxidant activities. Between the two fruits, $C$. carandas had higher phonolic content and antioxidant activity in all solvents suggesting the fruit could be a potential source of natural antioxidant for food and nutraceutical applications.
\end{abstract}

\section{INTRODUCTION}

Free radicals such as reactive oxygen species (ROS) and reactive nitrogen species are normally generated in human as part of its metabolism. The endogenous production of free radicals is enhanced by many external factors such as environment, food and medicine or by exposure to many pathological states. Antioxidants are molecules that neutralize free radicals by scavenging activity and reduce cellular damage [1]. Some of such antioxidants e.g. glutathione, ubiquinol and uric acid are produced during normal metabolism in the body [2]. When produced in increased concentration, free radicals particularly ROS damage important biomolecules and cellular constituents and hence are responsible for producing many life threatening diseases including cancer, hypertension, diabetes, atherosclerosis, inflammation, and premature aging [3, 4].

Recent research has confirmed that a high intake of fruits reduces the risk of some types of cancer and prevents heart

\footnotetext{
* Corresponding Author

Dwaipayan Sikdar, Department of Biochemistry and Molecular Biology, University of Chittagong, Chittagong-4331, Bangladesh.

E-mail:dsikdar @ cu.ac.bd
}

pathologies and Alzheimer's disease, owing to their high content in bioactive antioxidants such as polyphenols, vitamin $\mathrm{C}$, and carotenoids, which limit the available oxidation potential $[5,6]$. Interest in using these antioxidative agents in food, cosmetics and pharmaceutical products is increasing to replace synthetic antioxidants which are being restricted due to their carcinogenicity [7].

There are many techniques to recover antioxidants from plants, such as soxhlet extraction, maceration, supercritical fluid extraction, subcritical water extraction, and ultrasound assisted extraction. However, extraction yield and antioxidant activity not only depend on the extraction method but also on the solvent used for extraction. The presence of various antioxidant compounds with different chemical characteristics and polarities may or may not be soluble in a particular solvent [8]. Different solvent systems have been used to extract antioxidants from plant materials such as fruits, vegetables, legumes, and other foodstuffs. Water, aqueous mixtures of ethanol, methanol, and acetone are commonly used to extract antioxidants from plant foods [9]. The best solvent for extraction anthocyanins was $70 \%$ methanol whereas it was $70 \%$ acetone for the extraction of total phenolics, flavonoids and tannins from the eggplant [10]. Highest phenolic content and 
antioxidative activity was found in the extract of pineapple with absolute methanol [11] and the extract of black mulberries, blackberries and strawberries had the highest antioxidative activity with the mixtures of ethanol/water $(50 / 50, \mathrm{v} / \mathrm{v})$, acetone water/acetic acid (70:29.5:0.5, v/v/v) and 50\% acetone/water $(50 / 50, \mathrm{v} / \mathrm{v})$, respectively [12].

Study on the phenolic content and antioxidative properties of Bangladeshi fruits has drawn considerable attention now a day [13, 14]. Fruits of Artocarpus chaplasha Roxb. and Carissa carandas L. are two underutilized fruits of Bangladesh. A. chaplasha Roxb. (Synonyms: A. chama Buch.-Ham., Urostigma chrysophthalmum Miq.; Bengali name: Chapalish) belongs to the family Moraceae. It is a deciduous tree species. It is distributed throughout the sub-Himalayan track and outer hills from Nepal Eastwards ascending to Assam, Arunachal Pradesh, Bangladesh, Myanmar and Andaman [15]. The methanol extract of leaf of Artocarpus chaplasha Roxb. as well as its petroleum ether, carbon tetrachloride, chloroform and aqueous soluble partitionates were screened for antioxidant, cytotoxic, thrombolytic, membrane stabilizing and antimicrobial activities by Chowdhury et al. [16]. In vitro antioxidant property of $A$. chaplasha fruits was evaluated by Ahmed et al. [17] using methanol and petroleum ether as solvent. C. carandas L., generally known as coromda, is an ethnomedicinally important plant. The fruits, leaves, barks, and roots of $C$. carandas have been used in the treatment of human diseases, such as anorexia, intermittent fever, diarrhea, stomachic, syphilitic pain, burning sensation, mouth ulcer and sore throat, scabies, and epilepsy [18]. There are several studies on the phenolic content and antioxidative activities of $C$. carandas using absolute methanol [19], 70\% methanol [20], 40\% ethanol [21] and $80 \%$ acetone (for phenolic content) and methanol (for DPPH radical scavenging assay) [22]. To our knowledge, study on the effect of solvent in the phenolic compound extraction and antioxidant activity of these two fruits has not been reported yet. The purpose of this study is to determine and compare the polyphenolic contents and antioxidant activity of these two fruits as well as to select the solvent(s) that led to the extracts with highest antioxidant capacity.

\section{MATERIALS AND METHODS}

\subsection{Experimental sample}

Fresh matured fruits without any physical and microbial damage were collected from the markets of Chittagong, Bangladesh and were identified consulting Ahmed et al. [23, 24].

\subsection{Extract preparation}

The collected fruits were washed first with tap water thoroughly and then with deionized water. Edible parts of the fruits were collected, dried in the shade and ground into powder. Then, in a conical flask, $100 \mathrm{~g}$ of powder was mixed with $250 \mathrm{ml}$ of solvent using magnetic stirrer for $3 \mathrm{hr}$ in the dark at room temperature $\left(25^{\circ} \mathrm{C}\right)$ and filtered under suction (Whatman No. 1 filter paper). The contents on filter paper again transferred to the conical flask and the procedure repeated again. The two extract were pooled and dried with rotary evaporator. The resultant crude extract was weighed for yield calculation and stored at $4{ }^{\circ} \mathrm{C}$ until used. Methanol, ethanol, acetone and $50 \%, 70 \%$ aqueous solution of each as well as water were used as solvent for extraction. The crude extracts were dissolved in the respective extracting solvent in an appropriate concentration for subsequent experiments. All the analyses were done within three days of extraction.

\subsection{Determination of total phenols}

Total phenolic content in the fruit extracts was determined according to the Phenol-Ciocalteu method [25]. A 20 $\mu 1$ of sample aliquot of extract was added to $2.58 \mathrm{ml}$ distilled water followed by addition of $100 \mu \mathrm{l}$ of Folin-Ciocalteu reagent. After mixing, $300 \mu \mathrm{l}$ of $20 \%$ of sodium carbonate was added. The samples were vortexed and incubated at room temperature for $2 \mathrm{hr}$. The resulting blue colored solution was read at $765 \mathrm{~nm}$. A calibration curve was prepared, using a standard solution of gallic acid $\left(5-100 \mu \mathrm{g} / \mathrm{ml}, \mathrm{r}^{2}=0.997\right)$. Samples were analyzed in triplicates. The total phenolic content was expressed as mg gallic acid equivalent (GAE)/100 g dry weight (DW) of sample.

\subsection{Determination of total flavonoids}

Total flavonoid content of each extract was determined according to the colorimetric assay developed by Zhishen et al. [26]. To $300 \mu \mathrm{l}$ of extract, $4.8 \mathrm{ml}$ of distilled water and $0.3 \mathrm{ml}$ of $\mathrm{NaNO}_{2}(5 \% \mathrm{w} / \mathrm{v})$ were mixed. After 5 minute, $0.3 \mathrm{ml}$ of $(10 \% \mathrm{w} / \mathrm{v})$ $\mathrm{AlCl}_{3}$ and $2 \mathrm{ml}$ of $1 \mathrm{M}$ solution of $\mathrm{NaOH}$ were added and the volume was adjusted to $10 \mathrm{ml}$ with distilled water. The mixture was shaken vigorously and the absorbance was read at $510 \mathrm{~nm}$. A calibration curve was prepared using a standard solution of catechin $\left(20-100 \mu \mathrm{g} / \mathrm{ml}, \mathrm{r}^{2}=0.988\right)$. Total flavonoid content was expressed as milligram catechin equivalent (CE)/100 $\mathrm{g}$ of DW of sample.

\subsection{Radical scavenging activity using DPPH method}

Radical Scavenging activity of the fruit extracts were determined according to the method described by Hossain et al. [13]. Different concentration of each fruit extract was prepared in $1.5 \mathrm{ml} 50 \%$ ethanol (v/v) to which $0.5 \mathrm{ml}$ of $0.5 \mathrm{M}$ acetic acid buffer solution, $\mathrm{pH} 5.5$ and $1 \mathrm{~mL}$ of $0.2 \mathrm{mM}$ DPPH in ethanol were added and mixed vigorously. The reaction mixtures were incubated at room temperature in dark for 30 minute. A control was prepared as above without any extract. Change in the absorbance was measured at $517 \mathrm{~nm}$ and the results were expressed as inhibition percentage, calculated by the following formula:

$\%$ radical scavenging activity $=($ Control OD- sample OD/Control OD) $\mathrm{x} 100$.

The half-maximal inhibitory concentration $\left(\mathrm{IC}_{50}\right)$ was reported as the amount of antioxidant required to decrease the initial DPPH concentration by $50 \%$. 
Table 1: Extraction yields, total phenol and flavonoid contents of fruits extracted with different solvents.

\begin{tabular}{|c|c|c|c|c|c|c|}
\hline \multirow[b]{2}{*}{ Solvent } & \multicolumn{3}{|c|}{ A. chaplasha } & \multicolumn{3}{|c|}{ C. carandas } \\
\hline & $\begin{array}{l}\text { Extraction } \\
\text { Yield }(\%)\end{array}$ & $\begin{array}{c}\text { Total phenolic } \\
\text { content (mg } \\
\text { GAE/100 g DW) }\end{array}$ & $\begin{array}{c}\text { Total Flavonoid } \\
\text { content (mg CE/100 g } \\
\text { DW) }\end{array}$ & $\begin{array}{l}\text { Extraction } \\
\text { Yield }(\%)\end{array}$ & $\begin{array}{c}\text { Total phenolic } \\
\text { content (mg } \\
\text { GAE/100 g DW) }\end{array}$ & $\begin{array}{l}\text { Total Flavonoid content } \\
\quad(\mathrm{mg} \text { CE/100 g DW })\end{array}$ \\
\hline \multicolumn{7}{|c|}{ Methanol (\%) } \\
\hline 100 & 36.6 & $263 \pm 24$ & $619 \pm 28$ & 32.5 & $841 \pm 65^{a}$ & $848 \pm 33^{\mathrm{a}}$ \\
\hline 70 & 47.0 & $364 \pm 13^{\mathrm{ab}}$ & $92 \pm 10^{\mathrm{a}}$ & 29.5 & $756 \pm 33^{\mathrm{a}}$ & $686 \pm 79^{b}$ \\
\hline 50 & 47.7 & $413 \pm 12^{\mathrm{c}}$ & $95 \pm 8^{\mathrm{ab}}$ & 35.0 & $992 \pm 53$ & $639 \pm 40^{\mathrm{b}}$ \\
\hline \multicolumn{7}{|c|}{ Ethanol (\%) } \\
\hline 100 & 30.03 & $173 \pm 5$ & $1071 \pm 38$ & 26.8 & $533 \pm 25^{b}$ & $1070 \pm 81$ \\
\hline 70 & 47.0 & $375 \pm 4^{\mathrm{a}}$ & $104 \pm 4^{\mathrm{abc}}$ & 46.0 & $1082 \pm 106$ & $874 \pm 40^{\mathrm{ac}}$ \\
\hline 50 & 49.5 & $396 \pm 9^{c}$ & $97 \pm 6^{\text {abcd }}$ & 41 & $1273 \pm 50^{\mathrm{c}}$ & $789 \pm 47^{\mathrm{abcd}}$ \\
\hline \multicolumn{7}{|c|}{ Acetone $(\%)$} \\
\hline 100 & 12.3 & $64 \pm 1$ & $513 \pm 53$ & 16.0 & $236 \pm 42$ & $534 \pm 44$ \\
\hline 70 & 50 & $491 \pm 33$ & $179 \pm 4$ & 54.0 & $1957 \pm 54$ & $905 \pm 24^{\mathrm{ac}}$ \\
\hline 50 & 40.5 & $367 \pm 14^{\mathrm{d}}$ & $273 \pm 18$ & 35.0 & $1315 \pm 71^{\mathrm{c}}$ & $770 \pm 40^{\text {abd }}$ \\
\hline $\mathrm{H}_{2} \mathrm{O}$ & 47.5 & $356 \pm 2^{\text {bd }}$ & $101 \pm 11^{\mathrm{abcd}}$ & 32.0 & $529 \pm 38^{\mathrm{b}}$ & $273 \pm 15$ \\
\hline
\end{tabular}

\subsection{Statistical analysis}

Data were as mean \pm standard deviation of triplicate measurements. Data were statistically analysed using SPSS version. Statistical comparisons were performed with one-way analysis of variance (ANOVA) and the significant difference was set at $\mathrm{p}<0.05$.

\section{RESULTS AND DISCUSSION}

\subsection{Extraction yield}

Extraction of phytochemicals depends on the plant materials, solvent type, particle size and extraction technique. It is also influenced by the polarity of solvent, $\mathrm{pH}$, extraction time, temperature, sample-to-solvent ratio, no of repeats of extraction as well as by the chemical composition and physical characteristics of the plant sample. There is no single method for extracting all phenolic compounds from any particular plant sample [27, 28]. In this study, three different concentrations of methanol, ethanol, acetone in water $(50 \%, 70 \%$ and $100 \%)$ and water were used as solvent to obtain extracts of $A$. chaplasha and $C$. carandas fruits. The extraction yields of two fruits with different solvents are shown in Table 1. It is clear from data that extraction yields varied with solvents for both fruits. The extraction yield varied from $12.3 \%$ (with $100 \%$ acetone) to $50.0 \%$ (with $70 \%$ acetone) for $A$. chaplasha and from $16 \%$ (with $100 \%$ acetone) to $54 \%$ (with $70 \%$ acetone) for $C$. carandas. For both fruits it was found that the extraction yield increased with the polarity of the pure solvents. The result also showed higher extraction yield with aqueous solvent than the pure solvent. This might be due to extraction of both polar and nonpolar substances with aqueous organic solvents. Moreover, water can extract proteins and carbohydrates in addition to polar secondary metabolites. Similar pattern of change of extraction yield with solvents of different polarity was found with selected medicinal plant extracts [29], and with the extracts of Limnophila aromatica [8]. It was also found from the data that extraction yield of fruit $A$. chaplasha with water was very close to the yield by aqueous solvent whereas for fruit $C$. carandus the extraction yield was quite higher in aqueous solvent than water. This variation may be due to the difference in chemical composition of two fruits.

\subsection{Total phenolic content}

Phenolic contents of two fruits in different solvents are presented in table 1 . The phenolic contents of $A$. chaplasha fruit extracts were ranged from $64 \pm 1 \mathrm{mg}$ GAE/100 $\mathrm{g}$ DW for pure acetone to $491 \pm 33 \mathrm{mg}$ GAE$/ 100 \mathrm{~g}$ DW for $70 \%$ acetone. The results clearly indicate that the phenolic compounds of this fruit are hydrophilic. Whereas, phenolic contents of $C$. carandas were ranged from $236 \pm 42 \mathrm{mg} \mathrm{GAE} / 100 \mathrm{~g} \mathrm{DW}$ for pure acetone to $1957 \pm 54 \mathrm{mg}$ GAE/100 g DW for $70 \%$ acetone. In this study, between the two studied fruits, the phenolic contents of $C$. carandas were higher in all solvent extracts than the other fruit. Moreover, the phenolic contents varied significantly with solvent for both fruits indicating that the recovery of phenolic compounds is dependent on the solvent used in the extraction and its polarity. Like extraction yield, it was also found that the phenolic contents were higher in the aqueous solvent extracts than the pure solvent extract and $70 \%$ acetone extract had the highest phenolic content among the all extracts of the two fruits [491 $\pm 33 \mathrm{mg} \mathrm{GAE} / 100 \mathrm{~g}$ DW for A. chaplasha and 1957 $\pm 54 \mathrm{mg}$ GAE/100 g DW for $C$. carandus]. Extraction yield was also highest with this solvent from both fruits (table 1). Again, among all solvents, pure acetone extracts of both fruits showed the lowest phenolic contents $(64 \pm 1$ mg GAE/100 g DW for A. chaplasha and 236 $\pm 42 \mathrm{mg} \mathrm{GAE} / 100 \mathrm{~g}$ DW for $C$. carandus) as well as extraction yield. Aqueous acetone was found as efficient solvent for phenolic extraction in many previous studies, e.g. Kchaou et al. [30] found $70 \%$ acetone as the most potent solvent for extraction of phenolic compounds among five different solvents from six Tunisian date varieties. Furthermore, among the 19 different solvents, $70 \%$ acetone was the best solvent in extracting phenolics from three different berries [12]. Again Wijekoon et al. [31] showed that 50\% acetone extract had the highest phenolic content among seven different solvent extracts of bunga Kantan inflrorescence. Thus acetone which 
found as the weakest solvent for phenolic extraction in this study for both fruits, showed most efficient when mixed with water. This happened due to increased solvation provided by the presence of water [12]. However, the use of pure water as solvent is not efficient to extract phenols because these compounds are often more soluble in organic solvents less polar than water [32]. This is in agreement with the results obtained in the present study (Table $1)$.

The only reported study on the phenolic content of $A$. chaplasha fruit, extracted with methanol, by Ahmed et al. [17] found $41.12 \pm 1.83 \mathrm{mg}$ GAE/ $\mathrm{g}$ DW phenolic content which is significantly higher than the value $(263 \pm 24 \mathrm{mg} \mathrm{GAE} / 100 \mathrm{~g})$ found in the present study. This difference might be attributed to the ripening stage or geographical variation [33, 34]. On the other hand, phenolic content of the ethanolic extract of leaf, unripe and fully-ripe fruit extracts of $C$. carandas were $24.91 \pm 0.22,1.29 \pm 0.16$ and $4.67 \pm 0.41 \mathrm{mg} \mathrm{GAE} / \mathrm{g}$ as found by Pewlong et al. [21] which was $533 \pm 25 \mathrm{mg} \mathrm{GAE} / 100 \mathrm{~g}$ in this study. Sarma et al. [20] found $188.75 \pm 1.42 \mu \mathrm{g}$ GAE/g) phenolic content in the methanolic extract of $C$. carandas ( $841 \pm 65 \mathrm{mg} \mathrm{GAE} / 100 \mathrm{~g}$ in this study).

\subsection{Total flavonoid content}

Table 1 reports the flavonoid contents of two fruits in different solvent extracts. Unlike the phenolic content and extraction yield, flavonoid contents of both fruits were higher in the pure solvents than the aqueous solvents except the acetone extract of fruit $C$. carandus. Again, like the phenolic contents, flavonoid contents of fruit $C$. carandus were higher in all solvents than the other studied fruit except in the pure ethanol extract. The flavonoid content of different solvent extracts of fruit A. chaplasha were ranged from $92 \pm 10$ (in $70 \%$ methanol) to $1071 \pm 38$ (in pure ethanol) $\mathrm{mg} \mathrm{CE} / 100 \mathrm{~g} \mathrm{DW}$ whereas it was ranged from $273 \pm 15$ (in water) to $1070 \pm 81$ (in pure ethanol) $\mathrm{mg} \mathrm{CE} / 100 \mathrm{~g} \mathrm{DW}$ for $C$. carandas. Moderate negative correlation was found $(\mathrm{r}=-0.732)$ between phenolic and flavonoid content of A. chaplasha whereas the correlation was weak but positive $(\mathrm{r}=0.418)$ for $C$. carandas which is due to the different solubility of flavonoids from phenolics in different solvents. The negative correlations also indicate that the antioxidant activity of these fruits is attributed by phenolic compounds other than flavonoids especially for the fruit of A. chaplasha. Strong negative correlation between phenolic and flavonoid content was also reported for the medicinal plant $S$. scabrum [35].

\subsection{Antioxidant activity}

Antioxidant activity of the extracts of two fruits was measured by DPPH free radical scavenging assay. $\alpha, \alpha$-diphenyl- $\beta$ picrylhydrazyl (DPPH) free radical scavenging method offers the first approach for evaluating the antioxidant potential of a compound, an extract or other biological sources [36]. The \% scavenging activity of the extracts of two fruits were measured at different concentrations and are shown in Figure 1a and 1b. From the figures it is clear that all extracts of both fruits showed dose dependency. The concentration of an antioxidant needed to decrease the initial DPPH concentration by $50 \%\left(\mathrm{IC}_{50}\right)$ is widely used to evaluate the antioxidant capacity [10]. $\mathrm{IC}_{50}$ values were calculated from the dose dependency curve and are presented in table 2 . Here again, the $\mathrm{IC}_{50}$ values varied with solvents and fruits like phenolic content and extraction yield. The extracts of fruit $A$. chaplasha had the $\mathrm{IC}_{50}$ value in the range of $0.79 \mathrm{mg} / \mathrm{ml}$ (in $70 \%$ acetone extract) to $1.54 \mathrm{mg} / \mathrm{ml}$ (in $100 \%$ acetone extract), whereas, the range was $0.09 \mathrm{mg} / \mathrm{ml}$ (in $70 \%$ acetone extract) to $0.37 \mathrm{mg} / \mathrm{ml}$ (in $100 \%$ acetone extract) for the extracts of fruit $C$. carandas. Thus, like the extraction yield and phenolic content, highest antioxidant activity (lowest $\mathrm{IC}_{50}$ ) was found for $70 \%$ acetone and lowest antioxidant activity (highest $\mathrm{IC}_{50}$ ) was for $100 \%$ acetone of both fruits. The $\mathrm{IC}_{50}$ values of $C$. carandas were lower than those of $A$. chaplasha for all solvents representing former fruit as more powerful in antioxidant capacity. Strong correlation between phenolic content and $1 / \mathrm{IC}_{50}$ values were also found for fruit $A$. chaplasha $\left(\mathrm{R}^{2}=0.78\right.$, figure $\left.2 . \mathrm{A}\right)$ and fruit $C$. carandas $\left(\mathrm{R}^{2}=0.87\right)$ indicating that the antioxidant activities of the studied fruits are due to their phenolic contents.

Table 2: DPPH radical scavenging activity of different extracts.

\begin{tabular}{ccc}
\hline Solvent & \multicolumn{2}{c}{$\mathbf{I C}_{\mathbf{5 0}}(\mathbf{m g} / \mathbf{m l})$} \\
\cline { 2 - 3 } & A. chaplasha & C. carandas \\
\hline Methanol (\%) & 0.96 & 0.17 \\
100 & 0.93 & 0.13 \\
70 & 0.92 & 0.143 \\
\hline 0 & & 0.18 \\
\hline Ethanol (\%) & 1.53 & 0.13 \\
700 & 0.89 & 0.13 \\
50 & 0.95 & \\
\hline Acetone (\%) & & 0.37 \\
100 & 1.54 & 0.09 \\
70 & 0.79 & 0.11 \\
50 & 0.84 & 0.28 \\
$\mathrm{H}_{2} \mathrm{O}$ & 1.14 &
\end{tabular}

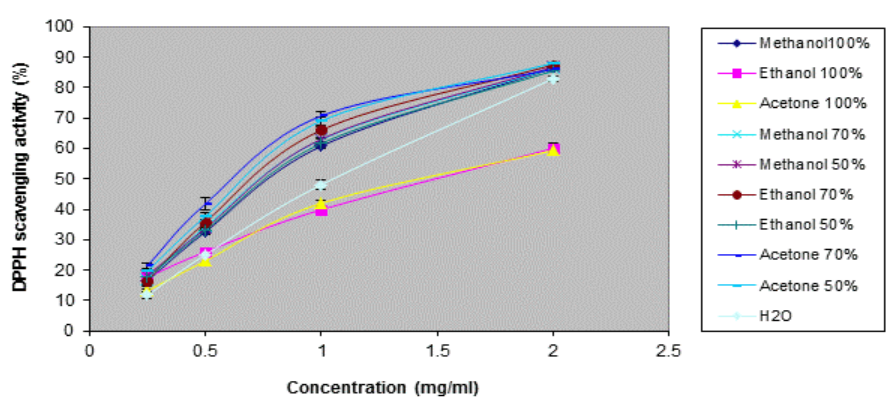

(a)

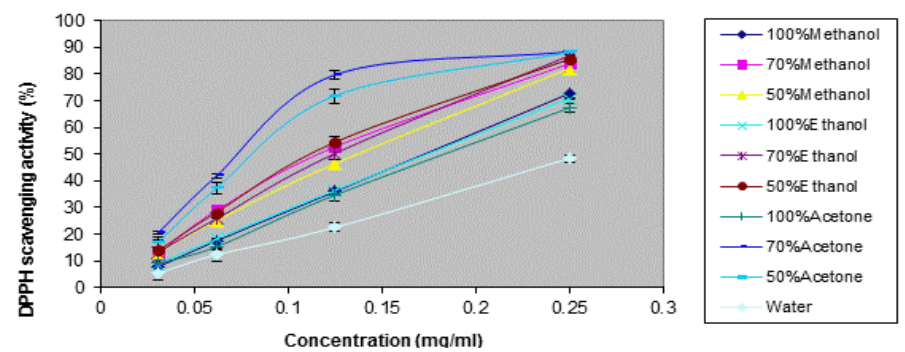

(b)

Fig. 1: Dose dependency of DPPH radical scavenging activity of (a) $A$. chaplasha and (b) C. carandas fruit extracts in different solvents. 

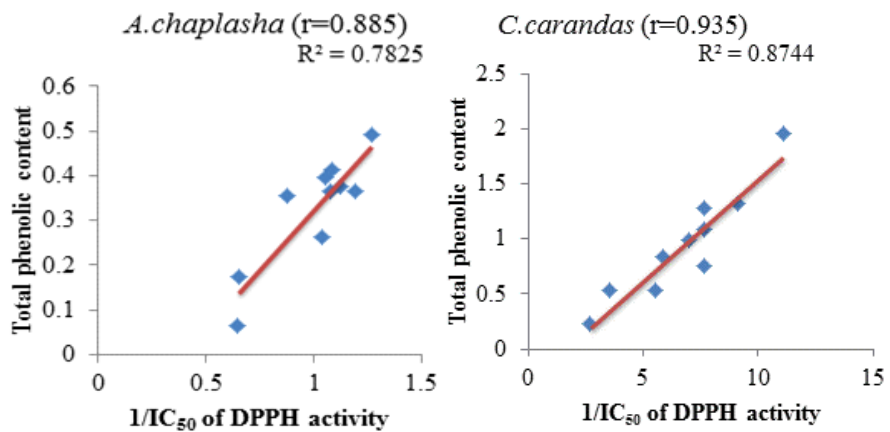

Fig. 2: Correlation between total phenolic content and antioxidant activity of studied fruit extracts.

\section{CONCLUSIONS}

The study clearly showed that solvents have great influence on the phenolic compound extraction and antioxidant capacity of the studied two fruits. Of all the solvents employed, $70 \%$ acetone was found to be the most efficient solvent in extracting phenolics with highest antioxidant capacity from both fruits and $100 \%$ acetone was the least efficient. Between the two fruits, $C$. carandas showed higher antioxidant potential and may be considered as a natural source of important phytochemicals with high antioxidant capacity.

\section{Financial support and sponsorship: Nil.}

Conflict of Interests: There are no conflicts of interest.

\section{REFERENCES}

1. Halliwell B. How to characterize an antioxidant- An update. Biochemical Society Symposium. 1995; 61:73-101.

2. Shi HL, Noguchi N, Niki N. Comparative study on dynamics of antioxidative action of $\alpha$ - tocopheryl hydroquinone, ubiquinol and $\alpha$ tocopherol, against lipid peroxidation. Free Radical Biology and Medicine. 1999; 27:334-46.

3. Chanaj-kaczmarek J, Wysocki M, Karachitos A, Wojcińska M, Bartosz J, Matlawska I, Kmita H. Effect of plant extract antioxidative phenolic compounds on energetic status and viability of Saccharomyces cerevisiae cells undergoing oxidative stress. Journal of Functional Foods. 2015; 16:364-377.

4. Lobo V, Patil A, Phatak A, Chandra, N. Free radicals, antioxidant and functional foods: impact on human health. Pharmacognosy Review. 2010; 4(8):118-126.

5. Murillo E, Britton GB, Durant, AA. Antioxidant activity and polyphenol content in cultivated and wild edible fruits grown in Panama. J Pharmacy and Bioallied Sciences. 2012; 4(4):313-317.

6. Zhang, Y, Gan R, Li S, Zhou Y, Li A, Xu D, Li H. Antioxidant phytochemicals for the prevention and treatment of chronic diseases. Molecules. 2015; 20: 21138-21156.

7. Velioglu YS, Mazza G, Gao L, Oomah BD. Antioxidant activity and total phenolics in selected fruits, vegetables, and grain products. J of Agricultural and Food Chemistry. 1998; 46:4113-4117

8. Do QD, Angkawijaya AE, Tran-Nguen PL, Huynh LH, Soetaredjo FE, Ismadji S. Effect of extraction solvent on total phenol content, total flavonoid content, and antioxidant activity of Limnophila aromatica. Journal of Food and Drug Analysis. 2014; 22: 296-302.

9. Xu BJ, Chang SKC. A comparative study on phenolic profiles and antioxidative properties of legumes as affected by extraction solvents. Journal of Food Science. 2007; 72(Nr. 2):S159-S166.
10. Boulekbache-Makhlouf L, Medouni L, Medouni-Adrar S, Arkoub L, Madani K. Effect of solvents extraction on phenolic content and antioxidant activity of the byproduct of eggplant. Industrial Crops and Products. 2013; 49:668-674.

11. Hossain MA, Rahman SMM. Total phenolic, flavonoids and antioxidant activity of tropical fruit pineapple. Food Research International. 2011; 44:672-676.

12. Boeing JS, Barizão EO, Silva BC, Montanher PF, Almeida VC, Visentainer JV. Evaluation of solvent effect on the extraction of phenolic compounds and antioxidant capacities from the berries: application of principal component analysis. Chemistry Central Journal. 2014; 8:48.

13. Hossain SJ, Tsujiyama I, Takasugi M, Islam MA, Biswas RS, Aoshima H. Total phenolic content, antioxidative, anti-amylase, antiglucosidase, and antihistamine release activities Bangladeshi fruits. Food Science and Technological Research. 2008; 14(3):261268.

14. Aklima J, Mojumder S, Sikdar D. Total phenolic content, reducing power, antioxidative and anti-amylase activities of five Bangladeshi fruits. International Food Research Journal. 2014; 21(1):119-124.

15. Rahman MS, Al-amin M, Akter S. Artocurpas chaplasha: Establishment and initial growth performance at elevated temperature and saline stresses. Journal of forest Science. 2012; 28(1):12-18

16. Chowdhury F, Pal S, Sharmin T, Rashid RB, Sikder MAA, Kabir S, Rahman MS, Rashid, MA. Bioactivities of Artocarpus chaplasha Roxb. and Bougainvillea spectabilis Willd. Bangladesh Pharmaceutical Journal. 2013; 16(1):63-68.

17. Ahmed T, Uddin MN, Ahmed SF, Saha A, Farhana K, Rana MS. In vitro evaluation of antioxidant potential of Artocarpus chama Buch. fruits. Journal of Applied Pharmaceutical Science. 2102; 2(10):075080.

18. Anupama N, Modhmita G, Rajesh KS. Role of dried fruits of Carissa carandas as anti-inflammatory agents and the analysis of phytochemical constituents by GC-MS. BioMed Research International. 2014; 2014:512369.

19. Wetwitayuklung $\mathrm{P}$, Charoenteeraboon $\mathrm{J}$, Limmatvapirat $\mathrm{C}$, Phaechamud T. Antioxidant activities of some Thai and exotic fruits cultivated in Thailand. Research Journal of Pharmaceutical Biological and Chemical Sciences. 2012; 3(1):12-21.

20. Sarma A, Sarmah P, Kashyap D, Dutta S, Mahanta M. Antioxidant activity and nutraceutical property of the fruits of an ethno-medicinal plant: Carrisa carandas L. found in Brahmaputra valley agro-climate condition. Journal of Pharmaceutical Sciences and Research. 2015; 7(2):55-57.

21. Pewlong W, Sajjabut S, Eamsiri J, Chookaew S. Evaluation of antioxidant activities, anthocyanins, total phenolic content, vitamin C content and cytotoxicity of Carissa carandas Linn. CMUJNS Special Issue on Food and Applied Bioscience. 2014; 13(1):509-517.

22. Kachhwaha P, Gehlot, HS. Changes in Phytonutrients and antioxidant properties of Cordia myxa and Carissa carandas fruit during ripening. Indian Journal of Plant Physiology. 2015; 20(1):7278.

23. Ahmed ZU, Hassan MA, Begum ZNT, Khondker M, Kabir SMH, Ahmad M, Ahmed ATA. Encyclopedia of Flora and Fauna of Bangladesh, Dhaka: Asiatic Society of Bangladesh. (Eds), 2009; Vol. 9, p. 186-187.

24. Ahmed ZU, Begum ZNT, Hassan MA, Khondker M, Kabir SMH, Ahmad M, Ahmed ATA, Rahman AKA, Haque EU. Encyclopedia of Flora and Fauna of Bangladesh, Dhaka: Asiatic Society of Bangladesh. (Eds), 2008; Vol. 6, p. 178.

25. Ough CS, Amerine MA. Phenolic compounds. In Methods for analysis of musts and wines. New York, USA: Wiley and Sons; 1998. p. 196-221.

26. Zhishen J, Mengcheng $\mathrm{T}$, Jianming $\mathrm{W}$. The determination of flavonoid contents in mulberry and their scavenging effects on superoxide radicals. Food Chemistry. 1999; 64:555-59. 
27. Dai J, Mumper RJ. Plant phenolics: extraction, analysis and their antioxidant and anticancer properties. Molecules. 2010; 15:73137352.

28. Khoddami A, welkes MA, Roberts TH. Techniques for analysis of plant phenolic compounds. Molecules. 2013; 18:2328-2375.

29. Sultana B, Anwar F, Ashraf M. Effect of extraction solvent/technique on the antioxidant activity of selected medicinal plant extracts. Molecules. 2009; 14:2167-2180.

30. Kchaou W, Abbès F, Blecker C, Attia H, Besbes S. Effects of extraction solvents on phenolic contents and antioxidant activities of Tunisian date varieties (Phoenix dactylifera L.). Industrial Crops and Products. 2013; 45:262- 269.

31. Wijekoon MMOJ, Bhat R, karim AA. Effect of extraction solvents on the phenolic compounds and antioxidant activities of Bunga kantan (Etlingera elatior Jack.) inflorescence. Journal of Food composition and Analysis. (2011); 24:615-619.

32. Meneses NGT, Martins S, Teixeira JA, Mussatto SI. Influence of extraction solvents on the recovery of antioxidant phenolic compounds from brewer's spent grains. Separation and Purification Technology. 2013; 108:152-158.

33. Gul J, Sultana B, Anwar F, Naseer R, Ashraf M, Ashrafuzzaman M. Variation in antioxidant attributes at three ripening stages of guava (Psidium guajava L.) fruit from different regions of Pakistan. Molecules. 2012;17:3165-3180.

34. Miletic N, Popović B, Mitrović O, Kandić M. Phenolic content and antioxidant capacity of fruits of plum cv. 'Stanley' (Prunus domestica L.) as influenced by maturity stage and on-tree ripening. Australian Journal of Crop Science. 2012; 6(4):681-697.

35. Anokwuru CP, Anyasor GN, Ajibaye O, Fakoya O, Okebugwu P. Effect of extraction solvents on phenolic, flavonoid and antioxidant activities of three Nigerian Medicinal Plants. Nature and Science. 2011; 9(7):53-61.

36. Kedare SB, Singh RP. Genesis and development of DPPH method of antioxidant assay. Journal of Food Science and Technology. 2011; 48(4):412-422.

\section{How to cite this article:}

Dhar G, Akther S, Sultana A, May U, Islam MM, Dhali M, Sikdar D. Effect of extraction solvents on phenolic contents and antioxidant capacities of $A$. chaplasha and $C$. carandas fruits from Bangladesh. J App Biol Biotech. 2017; 5 (03): 039-044. 